\title{
Síndrome de Zika congénito en la Argentina: presentación de dos casos clínicos
} Congenital Zika syndrome in Argentina: case series study

\author{
Dra. Analía Pastrana ${ }^{a}$ Dra. María Albarracin ${ }^{b}$ Dra. Marina Hoffmann ${ }^{a}$, Dra. Gabriela Delturco ${ }^{a}$, \\ Dr. René López $z^{a}$ Dr. Ramiro Gil ${ }^{a}$ Dr. Ariel Guzmán ${ }^{a}$ Dr. Mario Del Barco y Dr. Alberto Espeche ${ }^{a}$
}

\begin{abstract}
RESUMEN
En 2015, se observó un incremento en la incidencia de microcefalia congénita en recién nacidos en Brasil. Meses más tarde, se descubrió la relación causal entre el virus del Zika y estos hallazgos. Durante el primer brote en la Argentina, se reportaron 5 casos de síndrome de Zika congénito. En 2017, hubo un nuevo brote que involucró la provincia de Salta. En este trabajo, se presentan 2 casos clínicos con síndrome de Zika congénito autóctonos: una paciente con microcefalia congénita grave con lisencefalia, calcificaciones corticosubcorticales y ventriculomegalia y otra paciente con microcefalia posnatal con polimicrogiria asimétrica y calcificaciones subcorticales y retraso en la mielinización. El real impacto de esta enfermedad aún es incierto; es necesario un adecuado seguimiento multidisciplinario de los pacientes expuestos al virus del Zika para comprender mejor la infección y su historia natural.

Palabras clave: virus Zika, síndrome de Zika congénito, microcefalia.
\end{abstract}

\begin{abstract}
In 2015, there was an increase in the incidence of congenital microcephaly in newborns in Brazil. Months later, the causal relationshipbetweenZika virus and thesefindings was discovered. In Argentina, during the first outbreak there were 5 cases of congenital Zika syndrome reported. In 2017, there was a new outbreak which involved Salta province. We describe 2 patients with autochthonous congenital Zika syndrome: one of the babies with severe congenital microcephaly with lissencephaly, calcifications and ventriculomegaly; and another baby with postnatal microcephaly with asymmetric polymicrogyria, calcifications and delayed myelination. The real impact of this disease is still uncertain, so it is necessary an adequate multidisciplinary monitoring of patients exposed to Zika virus to better understand the infection and its natural history.

Key words: Zika virus, congenital Zika syndrome, microcephaly.
\end{abstract}

http: / / dx.doi.org/10.5546/ aap.2019.e635

Cómo citar: Pastrana A, Albarracín M, Hoffman M, Delturco G, et al. Síndrome de Zika congénito en la Argentina: presentación de dos casos clínicos. Arch Argent Pediatr 2019;117(6):e635-e639.

a. Servicio de Neurología.

b. Servicio de Neonatología.

Hospital Público Materno Infantil de Salta, Argentina.

Correspondencia:

Dra. Analía Pastrana: analia.pastrana@gmail.com

Financiamiento: Ninguno.

Conflicto de intereses: Ninguno que declarar.

Recibido: 11-10-2018

Aceptado: 2-7-2019

\section{INTRODUCCIÓN}

El virus del Zika (ZIKV) es un Flavivirus neurotropo. Se transmite por la picadura del mosquito hembra del género Aedes, como así también por vía sexual y vertical. Se aisló por primera vez en Uganda, en 1947. El síndrome de Zika clásico se caracteriza por fiebre, rash, poliartralgias y conjuntivitis. Las manifestaciones clínicas ocurren solo en el $20 \%$ de los afectados. El compromiso del sistema nervioso se describió, inicialmente, en 20132014, cuando se reportaron casos de síndrome de Guillain-Barre y meningoencefalitis asociados a la infección por ZIKV en la Polinesia Francesa. ${ }^{1}$

En 2015, la potencial asociación entre la infección materna por ZIKV y un síndrome congénito fue identificada en Brasil al observarse un aumento en la incidencia de microcefalia congénita en recién nacidos. ${ }^{2}$ En febrero de 2016, la Organización Mundial de la Salud (OMS) declaró emergencia de salud pública de importancia internacional y concluyó, luego de cinco meses, que el ZIKV era causa de microcefalia. ${ }^{3}$

En la Argentina, la Red Nacional de Anomalías Congénitas (RENAC) reportó un incremento de la prevalencia de microcefalia, y se detectaron 5 casos de síndrome de Zika congénito (SZC) durante el primer brote de ZIKV. En 2017, hubo un nuevo brote, que involucró a las provincias de Salta, Formosa y Chaco. ${ }^{4}$

El ZIKV es un nuevo miembro del grupo de las enfermedades infecciosas TORCHS (por las siglas de toxoplasmosis, otras enfermedades [como varicela, parotiditis, parvovirus y virus de la inmunodeficiencia humana], rubeola, citomegalovirus, herpes simple y sífilis), que produce una infección congénita, daña el cerebro en desarrollo, interfiriere con la multiplicación y migración de las células del sistema nervioso, acelera la apoptosis, altera la formación de mielina y la sinaptogénesis en el sistema nervioso central (SNC). ${ }^{5}$ 
El objetivo de este trabajo es presentar 2 casos clínicos con SZC autóctonos y describir sus características clínicas y neurorradiológicas.

\section{Caso clínico 1}

Bebé de sexo femenino derivada por microcefalia congénita a los 6 días de vida, sin antecedentes familiares relevantes. Durante la gestación, la madre había presentado un cuadro febril de causa desconocida. Nació por parto vaginal, de término, con peso adecuado y perímetro cefálico (PC) de $29 \mathrm{~cm}$ (-4 desvíos estándar-DE-). Presentó microcefalia grave (Figura 1), desproporción craneofacial, suturas cabalgadas, cuero cabelludo redundante, puente nasal ancho, reflejo cocleopalpebral ausente e hipertonía. Otoemisiones acústicas (OEA) ausentes, electroencefalograma sin focos ni paroxismos y evaluación oftalmológica normal. En la tomografía computada (TC) de cerebro, se observó lisencefalia, calcificaciones corticosubcorticales y ventriculomegalia (Figura 2). Análisis de laboratorio con serologías para ZIKV de la madre, inmunoglobulina $\mathrm{M}$ (IgM)-ensayo por inmunoabsorción ligado a enzimas (enzyme-linked immunosorbent assay; ELISA, por sus siglas en inglés) indeterminado con prueba de neutralización por reducción de placas (plaque reduction neutralization test; PRNT, por sus siglas en inglés) positiva y del bebé, IgM-ELISA positivo con PRNT positiva. Otras serologías para TORCHS fueron negativas. Evolucionó con retraso madurativo global grave y, a los 9 meses, desarrolló epilepsia. Actualmente, se encuentra en seguimiento multidisciplinario y neurorrehabilitación.

\section{Caso clínico 2}

Bebé de sexo femenino, derivada por microcefalia posnatal a los 2 meses de vida. Sin antecedentes perinatales ni familiares relevantes. Nació por cesárea por placenta previa, de término, con peso adecuado y PC de $34 \mathrm{~cm}$ (pc 50). Presentó PC de $35,2 \mathrm{~cm}$ (entre -2 y -3 DE), desproporción craneofacial, fontanela anterior puntiforme, cuero cabelludo redundante, reflejo cocleopalpebral ausente e hipertonía. OEA ausentes, con potenciales evocados auditivos de tronco encefálico (PEAT)

FIGURA 2. Tomografía computada de cerebro (axial). Se observa ventriculomegalia (flecha celeste), calcificaciones en la unión corticosubcortical y en los ganglios basales (fecha blanca) y lisencefalia (flecha roja)

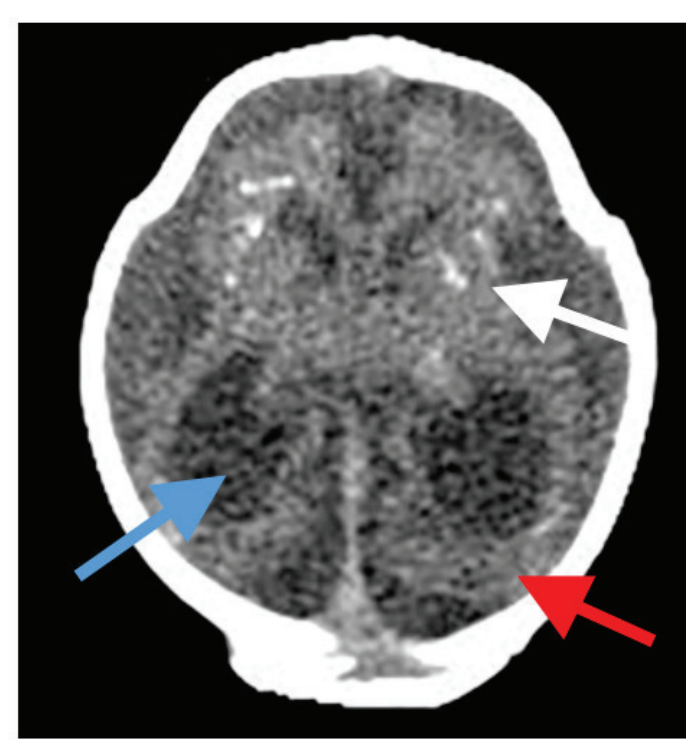

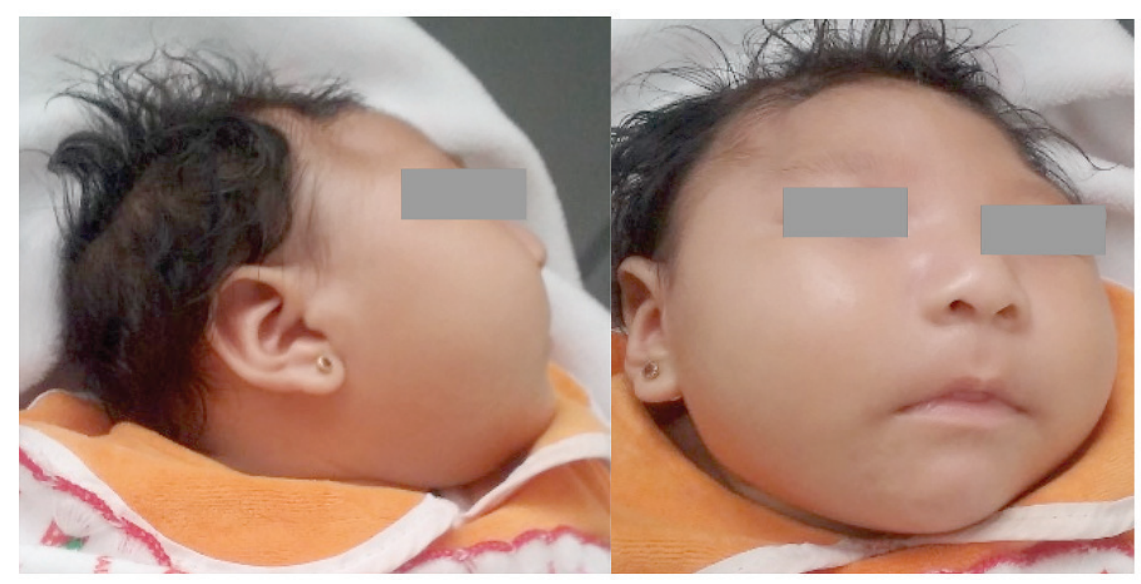


normales, electroencefalograma sin focos ni paroxismos y evaluación oftalmológica normal. En las neuroimágenes, se observó polimicrogiria asimétrica, calcificaciones subcorticales y retraso en la mielinización (Figura 3 y 4). Análisis de laboratorio con serologías para ZIKV de la madre, IgM-ELISA positiva con PRNT positiva y del bebé, IgM-ELISA positivo con PRNT positiva. Otras serologías para TORCHS fueron negativas. Evolucionó con retraso madurativo global con predominio motor grueso. Continúa con controles multidisciplinarios y neurorrehabilitación.

\section{DISCUSIÓN}

Nuestros pacientes presentaron microcefalia secundaria a infección congénita por ZIKV. Ambos casos provenían de áreas urbanas del norte de la provincia de Salta. Según el interrogatorio, las madres no habían realizado viajes a otras zonas de brote de ZIKV.

El SZC se caracteriza por manifestaciones clínicas y radiológicas similares a otras infecciones congénitas del grupo TORCHS. Presenta, principalmente, microcefalia asociada a anomalías cerebrales estructurales, oculares, alteraciones craneales e hipoacusia neurosensorial, ${ }^{3-5}$ con escasa repercusión sistémica. ${ }^{6}$ El riesgo de desarrollar SZC cuando la infección ocurre en el primer trimestre es del 1-13\%.3

El PC varía desde normal hasta grave microcefalia con significativa desproporción craneofacial, con un diámetro craneal vertical disminuido y prominencia occipital..$^{5-7}$ Se asocia a redundante cuero cabelludo, especialmente, en la zona occipital, la nuca y la frente. Otras anomalías craneofaciales son hipertelorismo, puente nasal plano y nariz corta. ${ }^{7}$ El caso 1 se presentó con microcefalia congénita grave y las anomalías craneofaciales detalladas previamente, ${ }^{5-7}$ mientras que el caso 2 tuvo microcefalia posnatal. La patogénesis de la microcefalia posnatal aún no está clara. ${ }^{8}$

Las a nomalías oculares reportadas son alteraciones maculares, como moteado grueso hiperpigmentado y/o atrofia coriorretiniana, y del nervio óptico con hipoplasia con signo del doble anillo, palidez y / o aumento de la relación copadisco, ${ }^{9}$ como así también microftalmia asimétrica, cataratas, herniación de la grasa periorbitaria, calcificaciones intraoculares, coloboma de iris y subluxación del cristalino. ${ }^{7}$ Nuestros pacientes tuvieron evaluaciones oftalmológicas normales.

La causa de hipoacusia neurosensorial en el SZC puede ser a nivel coclear o central. ${ }^{2}$ El compromiso auditivo encontrado en nuestros pacientes podría ser coclear; ambos tuvieron OEA negativas, y el caso 2 tuvo PEAT normales.

En relación con las alteraciones cerebrales estructurales, se describieron agiria, paquigiria, polimicrogiria, heterotopías y displasia cortical cerebelosa. $^{6}$

Las calcificaciones intraparenquimatosas
FIgURA 3. Tomografía computada de cerebro (axial). Se observan calcificaciones solo en la union corticosubcortical, paquigiria asimétrica (flecha roja)

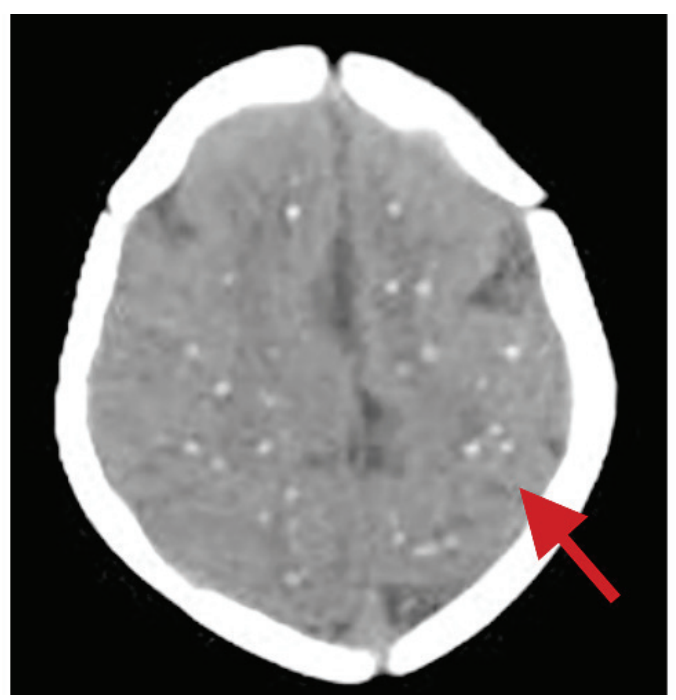

FIgURA 4. Resonancia magnética nuclear de cerebro (T2-coronal). Se observa polimicrogiria asimétrica, especialmente, a nivel frontal (flecha roja). Retraso en la mielinización

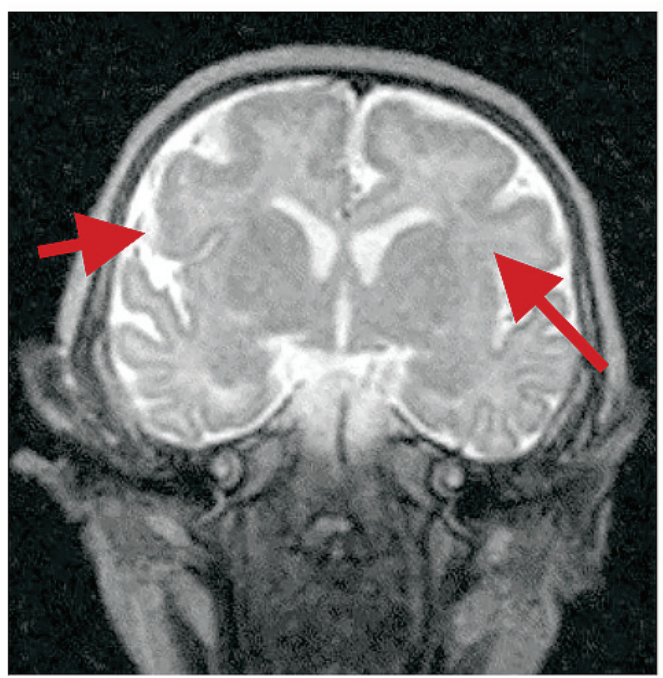


son más graves que en otras TORCHS, con morfología variada (puntiforme, en banda o aisladas), y se localizan, especialmente, en la unión corticosubcortical en los lóbulos frontal y parietal. Fueron detectadas también en los ganglios basales, el tronco encefálico y el cerebelo. $^{7}$

Asimismo, se reportaron ventriculomegalia, quistes subependimarios, aumento de los espacios subaracnoideos y megacisterna magna, hipoplasia, disgenesia o agenesia del cuerpo calloso. También se describieron hipomielinización e hipoplasia pontocerebelosa. ${ }^{10}$

Alrededor del $8 \%$ de los pacientes presentaron artrogriposis secundaria a compromiso del SNC y periférico. ${ }^{7-10}$ Se describieron hallazgos electromiográficos y de la resonancia magnética nuclear (RMN) de la columna sugestivos de compromiso de la motoneurona inferior. ${ }^{11}$ En relación con el compromiso medular, los pacientes con artrogriposis mostraron un aparente adelgazamiento de la médula espinal, con reducción de las raíces anteriores del cono medular. Este adelgazamiento comprometió por completo la médula espinal en casos con artrogriposis y fue predominantemente torácica en casos sin artrogriposis. ${ }^{7-12}$ Nuestros pacientes no tuvieron artrogriposis.

El espectro imagenológico del SZC tiene tres grados de gravedad. Una forma grave, con microcefalia al nacer, anomalías cerebrales mayores previamente descritas y apariencia simétrica; una forma intermedia, con microcefalia posnatal, que, a diferencia del grupo anterior, no presenta calcificaciones fuera de la unión corticosubcortical y agiria. Por último, una forma menos grave, sin microcefalia, que presenta únicamente calcificaciones restringidas a la unión corticosubcortical, áreas de paquigiria asimétrica, retraso en la mielinización y leve ventriculomegalia con apariencia asimétrica. La presencia de polimicrogiria asimétrica, principalmente, en los lóbulos frontales, se observó en pacientes sin microcefalia o con microcefalia posnatal. ${ }^{3-12-13} \mathrm{El}$ caso 1 pertenece a la forma grave de presentación, mientras que el caso 2 es una forma intermedia. La presencia de diferentes grados de gravedad estaría relacionada con el momento de la infección durante el embarazo.

Si bien la clínica descrita es común a las TORCHS, las anomalías craneales, la escasa repercusión sistémica y las calcificaciones en la unión corticosubcortical son sugestivas de SZC.
Alves et al., reportaron que la forma más frecuente de epilepsia en pacientes con SZC fueron los espasmos epilépticos. ${ }^{14} \mathrm{El}$ caso 1 evolucionó con epilepsia generalizada.

Las pruebas de laboratorio para detectar el ZIKV en forma directa -detección del ácido ribonucleico (ARN) viral por reacción en cadena de la polimerasa con transcriptasa inversa (reverse transcription polymerase chain reaction; $R T-P C R$, por sus siglas en inglés) - e indirecta (IgM-ELISA y $P R N T$ ) realizados a la madre y al niño permiten la confirmación del SZC. ${ }^{2-15}$ En el suero, el virus es detectable desde el comienzo de los síntomas, hasta el día 6 y, en la orina, a partir del día 5 hasta el día 15. La IgM es dosable a partir del día 4 y la inmunoglobulina $G(\operatorname{IgG})$, a partir del día 7 del inicio de los síntomas, y ambos persistirían en el suero hasta 12 semanas. ${ }^{2}$ El ARN del ZIKV se detectó hasta 6 meses en el semen y hasta 13 días en el tracto genital femenino desde el comienzo de los síntomas; ${ }^{1,2}$ esto último es importante considerar para la prevención de la transmisión vertical. En nuestros pacientes, se realizaron serologías que confirmaron el SZC y se descartaron otras infecciones congénitas.

En conclusión, si bien se describe un espectro de gravedad del SZC, el real impacto de esta enfermedad es aún incierto. Es importante, en los pacientes con microcefalia y calcificaciones cerebrales asociadas a malformaciones cerebrales, considerar la infección congénita por Zika entre los diagnósticos diferenciales. Asimismo, el SZC debería ser descartado en los pacientes que desarrollaran microcefalia posnatal durante el primer año de vida. Por último, existe un porcentaje de afectados con normocefalia, en los cuales la sospecha clínica es tardía y las posibilidades de confirmación mediante serología son escasas.

\section{REFERENCIAS}

1. Baud D, Gubler D, Schaub B, Lanteri M, et al. An update on Zika virus infection. Lancet. 2017; 390(10107):2099-109.

2. Tellechea A, Barbero P, Bidondo M, Groisman B, et al. Pautas de detección y seguimiento de niños y niñas nacidos con microcefalia $\mathrm{y} / \mathrm{o}$ anomalias cerebrales en el contexto de la emergencia por el virus Zika. Buenos Aires: RENAC-Ar/Unicef; 2017. [Acceso: julio de 2019]. Disponible en: http:/ / www.anlis.gov.ar/cenagem/wpcontent/ uploads / 2017 / 07 / PAUTAS-MICROCEFALIAy-ZIKA-RENAC-UNICEF.pdf.

3. Ribeiro BN, Muniz BC, Gasparetto E, Ventura N, et al. Congenital Zika syndrome and neuroimaginig findings: what do we know so far? Radiol Bras. 2017; 50(5):314-22.

4. Tellechea A, Luppo V, Morales M, Groisman B, et al. Surveillance of microcephaly and selected brain anomalies in Argentina: Relationship with Zika virus and other congenital infections. Birth Defects Res. 2018; 110(12):1016-26. 
5. Saad T, PennaeCosta A, De Góes FV, De Freitas M, et al. Neurological manifestations of congenital Zika virus infection. Childs Nerv Syst. 2018; 34(1):73-8.

6. Levine D, Jani J, Castro-Aragon I, Cannie M. How does imaging of Congenital Zika compare with imaging of other TORCH infections? Radiology. 2017; 285(3):744-61.

7. De Souza AS, de Oliveira-Szjenfeld PS, Melo AS, De Souza LAM, et al. Imaging findngs in congenital Zika virus infection syndrome: an update. Childs Nerv Syst. 2018; 34(1):85-93.

8. Van der Linden V, Pessoa A, Dobyns W, Barcovich J, et al. Description of 13 Infants born during October 2015-January 2016 with Conegnital Zika Virus Infection without microcephaly at birth - Brazil. MMWR Morb Mortal Wkly Rep. 2016; 65(47):1343-8.

9. Ventura C, Maia M, Ventura B, Van der Linden V, et al. Ophthalmological findings in infants with microcephaly and presumable intra-uterus Zika virus infection. Arq Bras Oftalmol. 2016; 79(1):1-3.

10. Aragao M, Brainer-Lima A, Holanda A, Van der Linden V, et al. Spectrum of Spinal Cord, Spinal Root, and Brain MRI Abnormalities in Congenital Zika Syndrome with and without Arthrogryposis. AJNR Am J Neuroradiol. 2017; 38(5):1045-53.
11. Van der Linden V, Filho E, Lins OG, Van der Linden A, et al. Congenital Zika syndrome with arthrogryposis: retrospective case series study. BMJ. 2016; 354:i3899.

12. Ribeiro B, Muniz B, Gasparetto E, Marchiori E. Congenital involvement of the central nervous system by the Zika virus in a child without microcephaly - spectrum of congenital syndrome by the Zika virus. J Neuroradiol. 2018; 45(2):152-3.

13. Aragao M, Holanda A, Brainer-Lima A, Petribu N, et al. Nonmicrocephalic Infants with Congenital Zika Syndrome Suspected Only after Neuroimaging Evaluation Compared with Those with Microcephaly at Birth and Postnatally: How Large Is the Zika Virus "Iceberg"? AJNR Am I Neuroradiol. 2017; 38(7):1427-34.

14. Alves L, Mello M, Bezerra P, Alves J. Congenital Zika Syndrome and Infantile Spasms: Case Series study. J Child Neurol. 2018; 33(10):664-6.

15. Administración Nacional de laboratorios e Institutos de Salud. Protocolo de vigilancia epidemiológica de la infección por virus Zika en embarazadas y recién nacidos. Buenos Aires: MINSAL; 2016. [Acceso: julio de 2019]. Disponible en: http:/ /www.anlis.gov.ar/wp-content/ uploads/2016/04/protocolo-zika-29-3-3.pdf. 